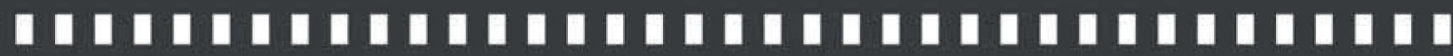 Fotografías en el espacio virtual: aspectos éticos y epistémico- metodológicos de su análisis en Ciencias Sociales

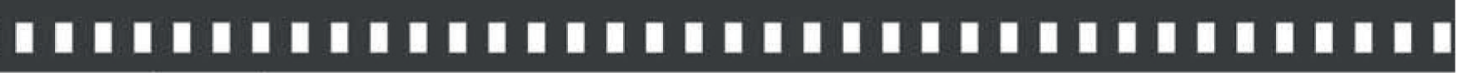

Patricia Karina

Natalia Schwarz

Artigo recebido em: 02/10/2015

Artigo aprovado em: 09/05/2016 


\title{
Fotografías en el espacio virtual: aspectos éticos y epistémico-metodológicos de su análisis en Ciencias Sociales
}

\author{
Photographs in the virtual space: ethical and epistemic-methodological \\ aspects of his analysis in Social Sciences \\ Patricia Karina Natalia Schwarz*
}

Resumen: El estudio de la fotografía necesita un abordaje metodológico especifico en el campo de las ciencias sociales, que pueda dar cuenta de dimensiones de análisis, desafios, alertas a considerar para el trabajo con material visual. En estas páginas desarrollamos aspectos epistemológicos y metodológicos del trabajo en ciencias sociales con fotografias, impresas y online; asi como también las implicancias y cuidados éticos que su uso requiere.

Palabras clave: Fotografía. Internet. Metodología. Ciencias sociales

\begin{abstract}
The study of photography requires a specific methodological approach in the field of social sciences, which could account for dimensional analysis, challenges, alert to consider for working with visual material. These pages develop epistemological and methodological aspects of work in social sciences with photographs, print and online; as well as the implications and ethical care that their use requires.
\end{abstract}

Keywords: Photography. Internet. Methodology. Social sciences

* Socióloga, Magíster en Investigación en Ciencias Sociales y Doctora en Ciencias Sociales (Summa Cum Laude) - Universidad de Buenos Aires. 


\section{Introducción}

Pensar acerca de los modos de aproximarnos a fenómenos sociales interpela a la integralidad de la experiencia en su constitución subjetiva, histórica y a la rigurosidad científica. La fotografía como recurso de análisis, es decir, en tanto dato construido para fines científicos, no puede escindirse de su implicancia en la construcción de sentido en la vida diaria para la población en estudio.

En Occidente la importancia de la imagen tiene relación con el proceso de fragmentación y consecuente jerarquización de partes del cuerpo humano. Desde el Iluminismo se priorizó lo visible y por ello los ojos cobraron protagonismo. En principio se destaca el rostro por otorgar identidad única, individualizada y distinguible en su particularidad (de modo funcional a los procesos de individualización); y dentro del rostro cobraron protagonismo los ojos, vía de acceso al conocimiento, manifestación del pensamiento, de la racionalidad. Cualidades, éstas últimas, que se tornaron hegemónicas en los procesos de modernización capitalista.

Nuestro interés en este artículo es abordar la imagen como territorio de experiencia y construcción de sentidos, en tanto espacio semantizable y por ello constituido también como ámbito definido por luchas de poder y de jerarquizaciones de sentido, de sujetos, de cuerpos, de experiencias.

La imagen encontró vías de propagación y presencia en la experiencia humana a través de diferentes soportes; uno de ellos es el digital e Internet en particular. En este trabajo analizamos las características propias de este último. Los sistemas digitales median en la comprensión del mundo a través de la modalidad de interfaz en la que dos dispositivos técnicos de comunicación asumen un rol central: la pantalla y la interfaz técnica. Esta última pone de manifiesto la transformación de la cultura basada en la escritura, en las estructuras narrativas logocéntricas y los contextos físicos, hacia la cultura digital orientada a lo visual, sensorial, retroactivo, no lineal y aparentemente inmaterial. Al igual que con la fotografía, 
aquí la interacción se da con la representación del mundo, no con el mundo mismo, se trata de una experiencia mediada. El poder de la imagen técnica conlleva la pérdida del posicionamiento central del individuo en un mundo iconofílico (SCHWARZ, 2013; GIANNETTI, 2007).

El cuerpo de este trabajo está organizado en 2 bloques: uno epistemológico y otro metodológico. Ambos se componen de dos aspectos: la fotografía en sí misma y la fotografía en el espacio virtual. Para finalizar abordamos algunas reflexiones generales y preguntas.

\section{Perfiles epistemológicos de la fotografía}

Desde sus orígenes la fotografía ha sido protagonista de interpretaciones y usos múltiples. Sin embargo, existe una dimensión que ha marcado la impronta de la forma de vincularse con ella a lo largo de su historia: su capacidad de reproducir escenas y objetos de la realidad, a partir de lo cual adopta una impronta de mímesis con lo real. Este aspecto ha sido materia de discusión y controversia desde sus inicios. De este modo, Phillipe Dubois (1986, p. 19) afirma acerca del realismo en la fotografía: "Existe un consenso de principio que pretende que el verdadero documento fotográfico rinda cuenta fiel del mundo". La condición de testimonio de la realidad se basa en el carácter mecánico y automático del proceso de producción de la imagen fotográfica, su génesis técnica. "La necesidad de ver para creer se encuentra allí satisfecha. La foto es percibida como una especie de prueba, a la vez necesaria y suficiente, que atestigua indudablemente la existencia de los que da a ver" (DUBOIS, 1986, p. 20).

Según Dubois (1986), esta percepción de la fotografía como una suerte de testimonio de la realidad transitó 3 momentos: 1- La fotografía en tanto espejo de lo real (el discurso de la mímesis). El efecto de realidad ligado a la imagen fotográfica ha sido atribuido 
a esta desde su advenimiento a partir de la semejanza entre la foto y su referente. Desde comienzos del S. XIX, la fotografía es considerada la imitación más exacta de la realidad. A partir de este momento histórico se producen desarrollos técnicos en una carrera por la verosimilitud, es decir, se intenta lograr una visión lo más real posible, lo más parecida a lo que el ojo humano puede proveer, e incluso aun mejor.

Dos textos desplazan la cuestión del realismo: "Ontologie de límage photographique" de André Bazin de 1945 y "Le Message photographique" de Roland Barthes de 1961. En el primero el automatismo en la constitución de la imagen no es designado como productor de semejanza. Sin embargo, "la ontología de la foto está en la contigüidad instantánea entre la imagen y su referente, en el principio de una transferencia de las apariencias de lo real sobre la película sensible. La idea de la huella, de la marca, está implícitamente presente en este tipo de discurso. El peso de lo real que la caracteriza proviene de su naturaleza de huella y no de su carácter mimético" (DUBOIS, 1986, p. 31). En el texto de Barthes "lo importante no es la idea de la perfección analógica, sino justamente la de mensaje sin código, que corresponde a la noción de génesis automática de Bazin" (BARTHES, 1989, p. 32). Esta corriente sitúa su objetivo en lo que Charles Peirce llamaría el orden del icono (representación por semejanza).

2-“La fotografía como transformación de lo real (el discurso del código y la deconstrucción)". En este momento se reacciona contra la percepción del momento anterior, es decir, contra el ilusionismo del espejo fotográfico.

"El principio de realidad fue designado entonces como pura impresión, un simple efecto. La imagen fotográfica, se intentaba demostrar, no es un espejo neutro sino un útil de trasposición, de análisis, de interpretación, incluso de transformación de lo real, en el mismo sentido que el lenguaje, por ejemplo, y como él, culturalmente codificado" (DUBOIS, 1986, p. 20). 
E1 S. XX aborda la transformación de lo real por la fotografía. Se trata de textos que se oponen al discurso de la mímesis y de la transparencia y se focalizan en considerar a la fotografía como una entidad codificada (en sentido cultural, técnico, sociológico, estético, etc.). También se mencionan las diferencias entre la imagen y lo real: tiene limitaciones en cuanto al ángulo de visión elegido, es decir, distancia respecto del objeto, el encuadre; además, reduce la tridimensionalidad a bidimensionalidad, reduce las variaciones cromáticas, excluye otras sensaciones que dan cuenta de lo real, tales como lo olfativo, lo táctil, en ocasiones (cuando no se trata del cine) también excluye lo sonoro.

Por un lado, tal como afirma Barthes, la comprensión de una fotografía requiere un aprendizaje de los códigos de lectura. El dispositivo fotográfico es por tanto un dispositivo culturalmente codificado. Por otro lado, una corriente considera la práctica del retrato fotográfico en tanto permite revelar una realidad o verdad interior: los retratistas.

Esta segunda perspectiva general, que considera a la fotografía como transformación de lo real, sitúa su objetivo en lo que Charles Peirce llamaría el orden del símbolo (representación por convención general).

3-“La fotografía como huella de un real (el discurso del índex y la referencia)". Se trata de un movimiento de deconstrucción semiológica y de denuncia ideológica. Sin embargo, inevitablemente la imagen remite a su referente. En este sentido desarrollan el análisis investigaciones posestructuralistas que encuentran apoyo en el concepto de índex de Charles Peirce (representación por contigüidad física del signo con su referente). Esta concepción se distingue de las mencionadas en el punto 1 y 2 porque considera que la imagen indicial está dotada de un valor singular, particular, puesto que está determinada solamente por su referente, así se convierte en huella de una realidad.

Peirce parte de considerar la fotografía desde su procedimiento técnico: una huella luminosa regida por leyes de la 
física y química. Así, se emparenta con otros signos tales como el humo, la cicatriz, la ruina; es decir, con signos que son afectados por su objeto, que mantienen con él una conexión física. En este sentido, estos signos se diferencian de los iconos (definido por una relación de semejanza) y de los símbolos (que definen su objeto por convención social). A pesar de que el índex se diferencia del icono y del símbolo, estos no son excluyentes uno de los otros. Por el contrario, las tres categorías semióticas aparecen como funciones teóricas distintas de un mismo mensaje y como clases de signos opuestos. Esto es porque ninguna de las tres categorías se manifiesta en estado puro y cada una se apoya en las otras dos.

Walter Benjamin en 1931 dijo aun antes que Roland Barthes, que en la fotografía el objeto referencial captado retorna, esa es la diferencia con la pintura y el dibujo. Barthes dice que en una fotografía no se puede negar que la cosa ha estado ahí. Hay una doble posición conjunta: de realidad y de pasado. Así, el noema de la fotografía es: eso ha sido. De esta manera, Barthes insiste sobre el realismo considerándola "mensaje sin código", volcándose a un tipo de referencialismo.

\section{La fotografía en tanto categoría epistémica}

Coincidimos con Barthes (1989) cuando afirma que el mensaje fotográfico establece una composición de significantes que acompañan a la imagen como reproducción de la realidad. La fotografía contiene un mensaje connotado y denotado. Barthes sostiene que si bien la imagen denotativamente funciona como un mensaje literal, analógico, sin código - a diferencia de la lengua, donde las denotaciones están codificadas-, connotativamente aludirá a significados codificados de tipo ideológico o cultural. De este modo, los signos lingüísticos vehiculan dos tipos de significados: un significado básico, de decodificación obligatoria, que se relaciona con la identificación de un referente específico 
(denotación) y un significado secundario, subsidiario, de decodificación aleatoria (connotación). En este proceso, el noema fotográfico refiere a una especificidad fotográfica: refiere a "esto ha sido". Esta característica de la imagen fotográfica la distingue de otros tipos de representación, como la lingüística (MARTÍNEZ DE AGUIRRE; BISELLI; MARENGO, 2000).

La imagen fotográfica es portadora de significados de producción social, mensajes que adquieren sentido en contextos específicos. De ahí también la potencialidad de este instrumento como formador de comportamientos. Por ejemplo, la construcción de la imagen corporal contemporánea está permeada de este instrumento.

Desde esta perspectiva es que podemos decir que la fotografía es una categoría epistémica: una categoría de pensamiento singular, que introduce una relación específica con los signos, con el tiempo, con el espacio, con lo real, con el sujeto, con el ser y con el hacer (DUBOIS, 1986). Así, podemos considerar al lenguaje fotográfico en tanto sistema u organización de signos que tiende a representar, simbolizar o designar otro objeto externo al sistema mismo (MARTINEZ DE AGUIRRE; BISELLI; MARENGO, 2000).

Siguiendo el enfoque de Peirce, el signo puede ser abordado en tanto algo que está en lugar de otra cosa en la percepción de alguien ${ }^{1}$. Esa realidad distinta de ellos mismos a la que los signos aluden en todo proceso de significación y en todo intercambio comunicativo, ha sido llamada referencia o referente. Este carácter animista de la imagen fotográfica es lo que impide, en ocasiones, romper o pisotear la foto de seres amados o una estampa religiosa (MARTÍNEZ DE AGUIRRE; BISELLI; MARENGO, 2000).

El álbum de familia es un ejemplo del carácter de fetiche y reliquia a la vez de la fotografía; pues, restituye la presencia física 1 El concepto de signo se remonta a los filósofos estoicos (S. IV a.C.), se lo retoma a comienzos del S. XX, dando origen a la Semiótica Contemporánea, en el trabajo de dos teóricos: el filósofo y lógico estadounidense Charles Peirce y el lingüista suizo de lengua francesa Ferdinand de Saussure (MARTINEZ DE AGUIRRE; BISELLI; MARENGO, 2000). 
del objeto. "Presencia que afirma la ausencia. Ausencia que afirma la presencia. Distancia establecida y abolida a la vez" (MARTÍNEZ DE AGUIRRE; BISELLI; MARENGO, 2000, p. 77). La distancia opera tanto en el espacio como en el tiempo. La imagen fotográfica, en tanto signo, está separada espaciotemporalmente de lo que ella representa y esta separación es constitutiva. "Toda foto implica que haya, bien diferenciados uno del otro, el aquí del signo y el allí del referente" (MARTÍNEZ DE AGUIRRE; BISELLI; MARENGO, 2000, p. 85). Diferenciar lo representado de su representación en la imagen es imprescindible para el análisis visual, es decir, no confundir la fotografía con un puro y lineal testimonio de una realidad sin mediaciones. Justamente estas mediaciones simbólicas son el terreno fértil a ser indagado en la investigación visual (PAUWELS, 2010).

De este modo entonces, abordar la imagen fotográfica en tanto categoría epistémica implica una forma de utilizar las imágenes como un modelo de pronunciamiento, una narrativa visual a través de la cual valores estéticos y documentales son representados y pasibles de una interpretación, de una hermenéutica visual (SILVA; PIRES, 2008).

Sin embargo, lograr interpretaciones requiere un proceso de construcción de sentido, el cual se puede ver impedido por la fragmentación de las prácticas científicas. A pesar de que se trata de un recurso metodológico disponible desde hace más de cuatro décadas, aún existen dificultades en la comunidad científica para consensuar la terminología técnica referida a los modos de abordaje de las imágenes, obstaculizando el intercambio entre colegas, el debate crítico acerca de su análisis, creación e interpretación. La fotografía en tanto herramienta para la investigación en ciencias sociales ha sido instrumentalizada e interpretada de diferentes modos, a partir de imágenes producidas por los investigadores, por la población bajo estudio, por personas anónimas o fotógrafos reconocidos tiempo atrás, recuperadas en documentos históricos o en álbumes familiares. Cada una de estas situaciones de creación de 
la imagen es analizada de modo diferente y con distintas técnicas audiovisuales, además de complementadas con el análisis de diversos datos secundarios -entrevistas, observaciones, diarios, archivos, etc.-, estos abordajes aun hoy no se nuclean en términos técnicos que puedan dar cuenta de su especificidad ni tampoco se ha desarrollado una metodología rigurosa específica para la producción, la sistematización, el análisis y la comunicación de las imágenes (BALOMENOU; GARROD, 2016; PAUWELS, 2010)².

\section{Abordajes metodológicos de la fotografía}

El recurso fotográfico para las investigaciones de campo ha sido parte de las ciencias sociales casi desde sus inicios, especialmente en la antropología (PELTO, 2015). Así, el abordaje metodológico de las imágenes fotográficas ha devenido en un abanico diverso de estrategias y sistematizaciones. Desde la perspectiva epistemológica con la que trabajamos, desarrollada en el apartado anterior, consideramos que es necesario analizar tanto los aspectos estéticos y técnicos como significativos de la imagen relevada. Para ello se requiere un trabajo de indagación histórica respecto de las herramientas tecnológicas y técnicas que mediaron en la producción de esa imagen, así como también en lo referido a las condiciones de contexto social de la misma.

Así, seguimos a Dubois (1986, p. 14) cuando afirma que

2 Paradójicamente, esta falta de integración en las prácticas y hallazgos de metodologías audiovisuales y de consenso en la comunidad científica se produce simultáneamente a una presencia cada vez mayor de las metodologías audiovisuales en ciencias sociales, que se expresa en la aparición creciente de revistas científicas especializadas, así como de organismos internacionales que nuclean a investigadores que desarrollan estos abordajes metodológicos, tales como: the International Visual Sociology Association (IVSA), the British Visual Sociology Group, the ISA Visual Sociology Thematic Group, the Visual Communication Studies Division of the International Communication Association (ICA), así como the International Visual Literacy Association (IVLA) (PAUWELS, 2010). 
"con la fotografía ya no nos resulta posible pensar la imagen fuera del acto que la hace posible". Esto quiere decir que se trata de una imagen-acto, en términos de este autor; es por ello que esta imagen-acto ontológicamente supone un sujeto en proceso. De esta manera, la imagen, en tanto dispositivo, pone en situación al sujeto y al que la mira. En esta línea de trabajo entonces, para poder realizar un análisis exhaustivo de la imagen es necesario responder a las siguientes preguntas: ¿qué es lo representado?, ¿cómo fue producido? Y ¿cómo es percibido?

Tomando estas preguntas como punto de partida y estructura ordenadora, el primer paso entonces refiere a lo fotografiado, a una descripción lo más detallada posible de todo lo contenido en la imagen analizada: colores, sujetos, objetos, situaciones, expresiones (gestos faciales, corporales, expresiones corporales), espaciotiempo, estética general, indumentaria, perspectiva, ubicación de sujetos y objetos en la imagen, entre otros aspectos.

En tanto instancia solidaria con la anterior, se hace necesario describir y sistematizar los datos de las condiciones de producción de la imagen: su autor (datos biográficos y sociohistóricos) ${ }^{3}$, sus características de contexto (momento histórico general, horario, lugar de realización de la imagen); técnica y tecnologías utilizadas; dar cuenta de si se trata de una imagen tomada de forma espontánea (si los sujetos fotografiados estaban al tanto de que eran parte de ese proceso o no), si requirió preparación de lo fotografiado y/o permisos previos o no; entre otros aspectos.

Luego, para complementar el análisis es necesario dar cuenta del destinatario, del receptor de la imagen: si la fotografía está destinada a algún receptor en particular o no, ¿por qué?, ¿para qué?, ¿un receptor abstracto, general o concreto, específico?

Para poder interpretar gran parte de los datos mencionados

3 La importancia de las características biográficas y particulares del autor de la imagen fotográfica es intrínseca al contenido significativo de la misma, ya que la consideramos una perspectiva, un fragmento de aquello que se quiso retratar, un dispositivo que crea sentido. Es por ello que Boris Kossoy (2001) alude al fotógrafo como filtro cultural. 
arriba, es imprescindible reconstruir y descifrar sus significados a través de datos complementarios (entrevistas y/o grupos focales realizados a los autores de las fotografías o a sus destinatarios o a sujetos emparentados con la situación de producción de la imagen, análisis historiográfico de documentos relativos a los aspectos mencionados arriba, datos estadísticos que den cuenta de las condiciones de contexto de la imagen, entre otros datos).

Tal como mencionamos en el apartado anterior referido a lo epistemológico, para poder llevar adelante el análisis de una imagen fotográfica desde la perspectiva planteada aquí es necesario desarrollar una descripción estética y técnica así como un análisis de los significados contenidos en esa imagen -es decir, analizar lo connotado y lo denotado- (BARTHES, 1989; DUBOIS, 1986).

De esta manera se da cuenta de componentes fundamentales de todos los procesos destinados a la producción de imágenes de cualquier especie: fotógrafo/a, tema y técnica específica/tecnología (KOSSOY, 2001).

Abordamos la imagen fotográfica en nuestro trabajo de investigación en los términos que describe nombre Kossoy (2001, p. 42): "La fotografía es testimonio y creación, en tanto binomio indivisible. Es un doble testimonio: por aquella que ella nos muestra de la escena pasada, irreversible, allí congelada fragmentariamente; y por aquello que nos informa acerca de su autor".

De esta manera estamos desarrollando dos instancias de análisis: una descripción iconográfica y un análisis iconológico. El análisis iconográfico tiene como meta detallar e inventariar sistemáticamente el contenido de la imagen en sus elementos icónicos formativos, esta instancia se sitúa a nivel de la descripción, no de la interpretación. Para lograr esto último se recurrirá a la "iconología" que permite la interpretación del significado intrínseco de la fotografía, que requiere la construcción de datos complementarios obtenidos de las entrevistas, grupos focales y observaciones (KOSSOY, 2001).

Las estrategias metodológicas antes mencionadas refieren 
tanto al análisis de una sola fotografía como a un corpus de fotografías. En este último caso, otro factor a considerar es el criterio de selección de imágenes que constituirán el corpus. Asimismo, si se tratara de un corpus de gran cantidad de fotografías facilita su abordaje la utilización de programas de análisis tales como el AtlasTi, que permite manejar un gran número de unidades fotográficas pudiendo sistematizar sus contenidos y notas de manera ordenada y cómoda para consultar durante el análisis.

La fotografía en tanto método de investigación científica permite además aplicar sus resultados también a políticas públicas y público general con mayor facilidad que otros tipos de datos científicos. Al mismo tiempo, promueve y requiere la multidisciplina para su análisis y creación (BALOMENOU; GARROD, 2015).

\section{Cuando la imagen analizada se encuentra en la pantalla del espacio virtual}

El advenimiento de nuevas tecnologías digitales de la imagen permite, entre otras cosas, la omnipresencia de ésta en la vida cotidiana de la población de gran parte del planeta. La cámara digital y los teléfonos celulares que la portan, así como webcams, y las plataformas llamadas redes sociales transformaron la práctica de la fotografía así como a lo fotografiable, sus significados, usos y funciones sociales; una de ellas, por ejemplo, la vigilancia y control. La masificación y facilidad de acceso de la imagen digital, sumado a la potencial difusión que tienen las imágenes en las redes sociales, son solidarias con la emergencia de fenómenos estilo Big Brother y/o Panóptico, mezclados con las lógicas de la sociedad del espectáculo. Así, la exposición y exhibición pública se convierten en una nueva forma de control y producción de la subjetividad. Edgar Gómez Cruz (2012), entre otros, apunta que la exhibición de imágenes privadas constituye la última fase de control capitalista, la imagen también se convierte en mercancía. 
Algunas problemáticas emergentes en los procesos digitales de circulación y producción de imágenes refieren a una región intermedia entre el voyeurismo de la intimidad y la distancia de la máscara. Este problema afecta a la percepción de autenticidad y a la tensión entre identidades e identificaciones; el proceso de comunicación mediada a modo computacional como experiencia sensorial, en tanto remite a una hibridación entre lo humano y la computadora, convierte a los usuarios del espacio virtual en cyborgs (DÍAZ DE RADA, 2008).

Los criterios de construcción de sentido de la Modernidad han coadyuvado a la emergencia de los dispositivos digitales de creación de imagen e información; con su énfasis en la racionalidad y el control, la importancia otorgada al conocimiento experto, como la ciencia, y el desarrollo de sus propias tecnologías clave: el reloj, el calendario, el mapa, las computadoras (HINE, 2004). Entre estos, el reloj y la estandarización del tiempo a nivel mundial, proceso que vacía su contenido específico, situado culturalmente; esto además, entre otros fenómenos, ha producido la separación entre tiempo y espacio que es retomada y profundizada por el ciberespacio. Aun así, más que trascender el tiempo/espacio, Internet puede ser representada como una instancia de múltiples órdenes espaciales y temporales que cruzan una y otra vez la frontera entre lo online y lo offline (HINE, 2004).

En el plano epistémico y ontológico de la fotografía, desarrollados anteriormente, no observamos una variación respecto de su expresión en el espacio virtual. Si bien existen diferencias entre los soportes y medios técnicos y tecnologías implementadas para la producción de las imágenes fotográficas, entre las que se cuentan las versiones en papel, en formato digital, entre otros; y si bien los modos de circulación y acceso a las fotografías también es diferente en cada caso, los procesos de construcción de sentido y la condición de índex, así como las características distintivas de la fotografía permanecen en los diferentes soportes.

Aun así, en el aspecto metodológico del abordaje de las 
imágenes fotográficas, existen particularidades en el trabajo con fotografías publicadas en el espacio virtual. Según Christine Hine (2004), cuando el investigador utiliza las herramientas cibernéticas para abordar el campo, se gana simetría en la exploración, pues el investigador emplea los mismos medios que sus informantes. Los desarrollos en etnografías móviles y multi-situadas también nos dan algunas guías para explorar la constitución de objetos etnográficos que atraviesan espacios geográficos junto a sus informantes. Tales desarrollos permiten pensar en la etnografía como modo de conocer a través de la experiencia sin pretender producir un estudio que abarque la totalidad de una cultura determinada y en tanto estrategia de abordaje metodológica comprometida con las situaciones de interacción social y no tanto con la locación, a la hora de definir y analizar su objeto de estudio.

Una problemática propia del espacio virtual como campo de construcción de datos científicos sociales es la dificultad en el armado del perfil sociodemográfico de los usuarios del espacio virtual analizado. En caso de contar con datos de este tipo, no es posible tener certeza acerca de si son fehacientes o no. Aquí es importante entonces focalizar el eje de la indagación en la construcción de sentido y en los mensajes circulantes en ese espacio, más que en los sujetos que lo llevan adelante.

En lo referido a la espacialidad de las indagaciones científicas en Internet, una etnografía realizada en el espacio virtual supone la realización de una etnografía multi-situada en tanto que atraviesa diferentes espacios geográficos. En estos espacios, los fenómenos a analizar son los usos y la construcción de sentido que se producen por medio de la tecnología referida al uso de Internet, en tanto está compuesta por un conjunto de tecnologías diversas y ensambladas. De este modo, su apropiación puede abordarse como una acumulación de prácticas que requieren diversos grados de experiencia y habilidad, que los sujetos adquieren en determinados sitios de traducción (cibercafés, hogares, escuelas o programas estatales) (GRILLO, 2007). 
Desde esta perspectiva entonces, es necesario considerar el concepto de territorio, en su sentido antropológico, en tanto espacio donde ocurren las relaciones socioculturales, un espacio habitado, así como también un entorno donde la vida comunitaria sucede. "Estas relaciones le imprimen al territorio un carácter subjetivo, ideológico, simbólico, ya que actúan como una mediación capaz de semantizarlo. Por eso, todo territorio habitado es un espacio socioculturalizado, y en consecuencia, es a partir del espacio social que cobra sentido el territorio" (RUIZ TORRES, 2008, p.21). Según Miguel Ángel Ruiz Torres (2008) existen dos formas de semantización territorial: la metonímica y la metafórica, ambas interactúan y son intrínsecas mutuamente. La primera, alude al significado del espacio en el proceso temporal, en el contexto cultural de su realización concreta. La semantización territorial metafórica hace referencia a la formalización simbólica que hace que un campo semántico sea relativo a una estructura social; es decir, que ciertos símbolos connoten mediante el proceso metafórico ciertas relaciones humanas.

Así, entre la pantalla y un individuo situado en un lugar hay una relación de correspondencia, el cuerpo y el territorio existen; sin embargo, la geografía es contingente pero no determinante, pues, ni el cuerpo ni el lugar donde éste está situado determinan por completo la existencia de la comunidad y la construcción de sentido. De este modo es que puede considerarse al ciberespacio en tanto territorio desde las ciencias sociales; y si la principal herramienta de adaptación social de los seres humanos constituye su capacidad simbólica, es innegable que el ciberespacio es un territorio semantizable, un espacio donde procesos metafóricos y metonímicos lo convierten en un lugar repleto de sentido (RUIZ TORRES, 2008).

La velocidad de cambio como marca distintiva de las prácticas de sentido que habitan el espacio virtual, herederas de la impronta moderna, son vehiculadas a través de estructuras iconográficas que permiten concentrar significados y leerlos con 
mayor velocidad. Así, la imagen concentra información permitiendo un rápido y fácil acceso, de ahí también su funcionalidad histórica en este momento (SCHWARZ, 2013).

\section{Consideraciones ético-metodológicas del análisis de fotografías publicadas en el espacio virtual}

La publicación de imágenes fotográficas online se ha convertido en un hábito para los usuarios de este espacio, tratándose de una práctica de muy fácil acceso, tanto para estos como para los cientistas sociales que investigan este campo. A partir de este escenario, se han desarrollado extensos debates acerca de problemáticas éticas en relación con la manipulación y análisis científico social de imágenes publicadas por los usuarios del espacio virtual, a pesar de lo cual no se ha llegado a establecer un criterio común (WILSON; PETERSON, 2002). En la investigación social visual las imágenes de situaciones que ocurren espontáneamente, es decir, sin reacción al investigador y su intervención, son muy valoradas por su dificultad de acceso y creación. Sin embargo, es éticamente cuestionado el acceso a estas imágenes sin el conocimiento de los sujetos que son parte de la imagen (PAUWELS, 2010).

Uno de los problemas éticos de estudiar fotografías de personas es que el cuerpo y particularmente el rostro, son utilizados por nuestra cultura como forma de individuación e identificación con enormes consecuencias que atraviesan transversalmente toda su existencia.

Existen perspectivas de investigaciones online que consideran que al tratarse de información con posibilidad de acceso público, subyace a la práctica de publicarlas el permiso a acceder libremente a las mismas sin pedir autorización. Para otras perspectivas este tipo de prácticas implican una suerte de 
intromisión que no respeta una expectativa implícita de privacidad por parte de los sujetos estudiados.

Coincidimos con Samuel Wilson y Leighton Peterson (2002) en que en caso de desarrollarse una investigación online el investigador debe obtener un consentimiento informado de las personas retratadas en las fotografías con las que se trabajará en la investigación, así como debe respetar las leyes de propiedad intelectual de imágenes fotográficas registradas en términos comerciales. A partir de considerar la antropología online al igual que la offline, es necesario respetar a los sujetos en estudio y proteger su dignidad, intereses y anonimato al igual que en los estudios sociales realizados cara a cara.

La dificultad de establecer criterios comunes en el trabajo científico social con fotografías online en parte está vinculado al apagamiento de los límites entre el espacio público y privado del espacio virtual (GÓMEZ CRUZ, 2012). Al mismo tiempo, el hecho de que exista un acceso posible a los datos personales sin necesidad de contar con permiso expreso o consentimiento informado habilita a que buscar obtenerlos sea prescindible en cuanto a la viabilidad de desarrollar una investigación online y quede en la decisión de cada investigador hacerlo o no. Aun los comités de ética no han consensuado políticas al respecto.

Algunos investigadores optan por interactuar con la población en estudio en iguales condiciones, es decir, muestran datos suyos y se exponen del mismo modo que observa los de los demás. Y cuando interactúan en foros con las personas estudiadas manifiestan abiertamente sus intenciones como investigadores, así como comentan lo relativo a las preguntas de investigación. Abordar la interacción con los sujetos en estudio durante el trabajo de campo con honestidad.

Tal como afirma Arturo Escobar (2005), se hace necesario analizar el campo de utilización de estas tecnologías desde una perspectiva que considere la forma en que éstas permiten negociar formas de construcción de poder, autoridad y representación, entre 
los usuarios del espacio virtual así como con los cientistas sociales que los investigan.

\section{Algunas palabras finales}

Vivimos en una era audiovisual, la fotografía estructura la experiencia de los sujetos, es por ello que consideramos relevante incluirlo como medio para interpretar fenómenos sociales. Desde su capacidad de construcción simbólica, la experiencia humana es mediada y la fotografía es una mediación más dentro de ésta. En esta sinergia de sentidos en la que la tecnología es solidaria con procesos ontológicamente humanos, la lente y el ojo humano se miran mutuamente en la fotografía. Pero en el encuentro de sus miradas se establece una jerarquización de lo representado en la imagen, pues se trata de un proceso de selección de perspectivas y elementos dentro de un encuadre determinado.

Tal como afirma Boris Kossoy:

"Sea como medio de recordación y documentación de la vida familiar, sea como medio de información y divulgación de los hechos, sea como forma de expresión artística, o inclusive como instrumento de investigación científica, la fotografía ha formado parte indisociable de la experiencia humana. El fragmento de la realidad grabado en la fotografía representa el congelamiento del gesto y del paisaje, y por lo tanto la perpetuación de un momento, en otras palabras, de la memoria: memoria del individuo, de la comunidad, de las costumbres, del hecho social, del paisaje urbano, de la naturaleza. La escena registrada en la imagen no se repetirá jamás. El momento vivido, congelado por el registro fotográfico, es irreversible" (KOSSOY, 2001, p. 118).

Oscar Grillo (2007) propone abordar el estudio del uso de las 
tecnologías desde el aspecto geográfico, tecnológico (informática y biotecnología) y disciplinar (ciencias sociales). En este sentido, no perder de vista la impronta del momento histórico de su emergencia: la Modernidad con su característica universalización del conocimiento y la acumulación y circulación de capital, así como las lógicas de consumo que acompañan los modos de producción capitalista.

Las nuevas tecnologías de información y comunicación plantean nuevos escenarios de situación en los que las culturas y sus mitos pueden entrar en contacto modificándose mutuamente, aportándose nuevas miradas y cuestionando las previas. Frente a la estandarización identitaria y de estilos de vida que plantean estas tecnologías de modo articulado con las lógicas y los mercados de consumo, se gestan nuevas configuraciones simbólicas y normativas a partir del contacto y confluencia de diferentes culturas en el ciberespacio (SCHWARZ, 2013). Los desplazamientos en las formas de construcción de subjetividad, de fragilidad e inestabilidad del yo visible, exteriorizado y alterdirigido, que estas tecnologías están generando aun no han dicho su última palabra. Nos remite a reconocer que el conocimiento en ciencias sociales está constantemente en proceso, por ello es incompleto y está permeado del constreñimiento que le otorga su carácter de perspectiva (PAUWELS, 2010; SIBILIA, 2008). En definitiva se trata de sumergirse en las estrategias de construcción de sentido, en tanto proceso nunca acabado presenta un desafío ya conocido para las ciencias sociales respecto de las incertidumbres y emergentes a abordar.

\section{Referencias}

BALOMENOU, Nika; GARROD, Brian. A review of participantgenerated image methods in the social sciences. Journal of Mixed Methods Research, Ann Arbor, v. 10, n. 4, p. 1-17, 2016. 
BARTHES, Roland. La cámara lúcida: nota sobre la fotografía. Barcelona: Paidós, 1989.

DÍAZ DE RADA, Ángel. La mediación computacional de la comunicación y la lógica de la investigación etnográfica: algunos motivos de reflexión. In: ARDÈVOL, Elisenda; ESTALELLA, Adolfo; DOMINGUEZ, Daniel (Orgs.). La mediación tecnológica en la práctica etnográfica. La Vascongada: Ankulegi, 2008.

DUBOIS, Philipe. EI acto fotográfico. : de la representación a la recepción. Barcelona: Paidós, 1986.

ESCOBAR, Arturo. Bienvenidos a Cyberia. Notas para una antropología de la cibercultura. Revista de Estudios Sociales, Bogotá, n. 22, p. 15-35, diciembre de. 2005.

GIANNETTI, Claudia. La realidad de-mente y la socialización link. In: SCHULTZ, Margarita (Org.). El factor humano en la cibercultura. Buenos Aires: Alfagrama, 2007.

GÓMEZ CRUZ, Edgar. De la cultura Kodak a la imagen en red:. una etnografía sobre fotografía digital. Barcelona: Editorial UOC, 2012.

GRILLO, Oscar. Internet como un mundo aparte e internet como parte del mundo. In: CÁRDENAS, Miriam; MORA, Martín(Orgs.). Ciberoamérica en red. escotomas y fosfenos 2.0. Barcelona: Editorial UOC, 2007.

HINE, Christine. Etnografía virtual. Barcelona: Editorial UOC, 2004.

KOSSOY, Boris. Fotografía e historia. Buenos Aires: Ed. La Marca, 2001. 
MARTÍNEZ DE AGUIRRE, Elizabeth; BISELLI, Rubén; MARENGO, Mirtha. Introducción a los lenguajes:. la fotografía. Rosario: Laborde Ed., 2000.

PAUWELS, Luc. Visual sociology reframed: an analytical synthesis and discussion of visual methods in social and cultural research. Sociological Methods \& Research, Beverly Hills, v. 38, n. 4, p. 1-37, 2010.

PELTO, Pertti J. What is so new about mixed methods? Qualitative Health Research, Thousand Oaks, v. 6, n. 25, p. 734-745, Jun.e 2015.

RUIZ TORRES, Miguel A. Ciberetnografía: comunidad y territorio en el entorno virtual. In: ARDĖVOL, Elisenda; ESTALELLA, Adolfo; DOMINGUEZ, Daniel (Orgs.). La mediación tecnológica en la práctica etnográfica. La Vascongada: Ankulegi, 2008.

SCHWARZ, Patricia K. N. Intimidad con/en la pantalla. Re/ interpretaciones de la sexualidad y las relaciones sexoafectivas en la arena digital. In: SCHWARZ, P. K. N.; MENDES DIZ, Ana María (Orgs.). Sexualidades, género y otras relaciones políticas en el espacio virtual: oportunidades, desafíos y nuevas sociabilidades. Buenos Aires: UBA, 2013. Disponível em: <http://iigg.sociales. uba.ar/2013/09/03/documentos-de-trabajo-no-68/>. Acesso em: 15 fev. 2017.

SIBILIA, Paula. La intimidad como espectáculo. Buenos Aires: Fondo de Cultura Económica, 2008.

SILVA, Sérgio L. Pereira da; PIRES, Maria da Conceição Francisca. Identidades visuales: video y fotografía en las formas de representación de la identidad de Río de Janeiro. In: ARDĖVOL, Elisenda; ESTALELLA, Adolfo; DOMINGUEZ, Daniel (Orgs.). 
La mediación tecnológica en la práctica etnográfica. La Vascongada: Ankulegi, 2008.

WILSON, Samuel M.; PETERSON, C. Leighton. The anthropology of online communities. Annual Review of Anthropology, Palo Alto, v. 31, pp. 449-467, June. 2002. 